\title{
U.S. Cyber Strategy of Persistent Engagement \& Defend Forward: Implications for the Alliance and Intelligence Collection
}

\author{
Intelligence and National Security \\ 'Perspectives on Intelligence' Section
}

\author{
Max Smeets \\ ETH Zurich, Center for Security Studies \\ MSmeets@ethz.ch
}

Abstract: The 2018 U.S. Cyber Command vision and the Department of Defense Cyber Strategy embody a fundamental reorientation in strategic thinking. Much has been written about the implications of U.S. change in strategic doctrine for great power dynamics. Yet, less systematic attention, has been devoted to the strategy's implications for the alliance and intelligence collection. The purpose of this Perspective is to conduct a benefit-risk assessment of the US strategy on these issues. Whilst the U.S.'s mission to persistently engage with adversaries may have benefits for alliance relationships, the paper identified four avenues how the strategy leads to negative implications for the alliance i) loss of trust due to offensive cyber effects operations in allied systems or networks; compromise of allied intelligence operations and capabilities; iii) exploitability of the strategy by adversaries; and iv) the implementation (and justification) of persistent engagement by other countries. The paper suggests several ways forward, including the promoting of new NATO-memorandum of understanding on cyber operations.

Key words: U.S. Cyber Command, Persistent Engagement, Defend Forward, Allies, cyber operations 


\section{U.S. Cyber strategy of Persistent Engagement \& Defend Forward: Implications for the Alliance and Intelligence Collection}

The 2018 U.S. Cyber Command vision and the Department of Defense Cyber Strategy embody a fundamental reorientation in strategic thinking. ${ }^{i}$ Based on the recognition that adversarial behavior below the threshold of armed attack could nevertheless be strategically meaningful, U.S. Cyber Command seeks to achieve "superiority through persistence", that is constantly engaging with the adversary - wherever they maneuver. ${ }^{\text {ii }}$

Much has already been written about the implications of U.S. doctrinal change. The strategic shift has, in particular, led to numerous critical remarks about the risks of escalation between the U.S. and its main adversaries in cyberspace. ${ }^{\text {iii }}$ Early on, Healey voiced concern that the change in strategy would trigger the "new forever war in cyberspace". iv In a more recent article, Healey analyzes the implied causal chain of "persistent-engagement stability theory," and addresses how certain feedback loops could potentially amplify or dampen cyber conflict. ${ }^{\mathrm{v}}$ Others have argued that persistent engagement deepens the cyber security dilemma - especially between the U.S. and China. ${ }^{\mathrm{vi}}$

The degree to which persistent engagement can help with the establishment of cyber norms has opened a second line of debate. According to some proponents, persistent engagement is a form of norms setting through practice, leading to a "comprehensive strategic great power competitive space with its own distinct structural features." vii Others are less positive that the strategy can create a new normative area of competition - especially if it is not combined with other elements of competitions in the economic, diplomatic, informational and military spheres. ${ }^{\text {viii }}$

In addition, the shift in U.S. strategy together with a set of notable legal changes - particularly to the authorisation and oversight architecture - has led scholars and practitioners to write more prolifically about U.S. legal underpinnings of out-of-network operations. ${ }^{\text {ix }}$ As a workshop report on military cyber operations clarifies, three changes are most prominent: "Firstly, the changes confirmed that the [DoD] has authority to operate in the cyber domain outside of the context of defending its own networks. Secondly, they clarified when the executive can decide on the undertaking of operations outside US territory without Congressional authorisation. [...] Thirdly, Congress explicitly articulated that the activity conducted by U.S. Cyber Command does not constitute "covert action" as defined by US domestic law." 'Overall, scholars have concluded that U.S. Cyber Command can now operate more swiftly as it is no longer required to undertake the interagency process as before. ${ }^{\mathrm{xi}}$

Less systematic attention, however, has been devoted to the strategy's implications for the alliance and intelligence collection. The purpose of this paper is to conduct a benefit-risk assessment of the US strategy on this issue. ${ }^{\mathrm{xii}}$ The assessment of this article takes place in five steps. Section I notes that, historically, allied states operate in each other's systems or networks in at least two ways: as an observer, gathering intelligence on adversarial activity in others' networks; and as a passerby, transiting through 
allied systems and networks to access a certain adversarial target. It is argued that, with the change in strategy, the U.S. now also seeks to be a disrupter, seeking to cause friction for an adversary's operation within an ally's network or system. Section II addresses the benefits of this activity and efforts of the U.S. to more closely collaborate with allies in this space. It suggests US strategy of persistent engagement and defend forward can promote a stronger defense as a whole - and for states with limited cyber capability in particular. ${ }^{\text {xiii }}$ Section III subsequently discusses the four avenues of how the strategy could lead to negative implications for the alliance: i) loss of trust due to offensive cyber effects operations in allied systems or networks; compromise of allied intelligence operations and capabilities; iii) exploitability of the strategy by adversaries; and iv) the implementation (and justification) of persistent engagement by other countries. The final section concludes and provides a potential proposal to move forward.

\section{Out of Network Operations in allied systems or networks}

The purpose of this section is to review the nature of U.S. Cyber Command's out of network operations. The first part talks about the understanding of territoriality and cyber operations. The second part discusses three types of out of network operations in allied networks.

Following its change in strategy, U.S. Cyber Command seeks to operate "seamlessly, globally and continuously." seizes and maintains the initiative in cyberspace by continuously engaging and contesting adversaries and causing them uncertainty wherever they maneuver." ${ }^{\mathrm{xv}}$ In an article for Joint Force Quarterly, NSA Director and Cyber Command head Gen. General Nakasone writes: "If we are only defending in "blue space," we have failed. We must instead maneuver seamlessly across the interconnected battlespace, globally, as close as possible to adversaries and their operations, and continuously shape the battlespace to create operational advantage for us while denying the same to our adversaries"xvi

"As close as possible" means that the US seeks to achieve effects i) outside of its own networks, and ii) beyond adversaries networks. This vast area is not ungoverned space. We are talking here about routers in Nairobi, servers in the Denmark, or operating infrastructure in other countries. As Seymour Goodman put it "cyberspace always touches ground somewhere". xvii

Yet, U.S Cyber Command's use of terminology - as well as talk about "operating close to the adversary" - evades one issue: It is unclear whether Cyber Command only seeks to cause friction in "red space" or if it seeks to compete in "gray space" as well. These terms are often confused and not wellunderstood. In fact, the issue was raised for "further exploration" at Cyber Command's 2018 symposium, specifically understanding the "relevance of concepts like area of responsibility and redblue-gray space to the cyberspace domain." "xviii Joint Publication 3-12 (JP 3-12) on cyberspace operations, prepared under the direction of the chairman of the Joint Chiefs of Staff, explains the terminology: 
The term "blue cyberspace" denotes areas in cyberspace protected by the US, its mission partners, and other areas DOD may be ordered to protect. [...] The term "red cyberspace" refers to those portions of cyberspace owned or controlled by an adversary or enemy. In this case, "controlled" means more than simply "having a presence on," since threats may have clandestine access to elements of global cyberspace where their presence is undetected and without apparent impact to the operation of the system. Here, controlled means the ability to direct the operations of a link or node of cyberspace, to the exclusion of others. All cyberspace that does not meet the description of either "blue" or "red" is referred to as "gray" cyberspace. ${ }^{\text {xix }}$

Gray space is defined based on the 'nodes' adversaries control. This means the vast area between U.S. government-owned networks and adversaries is not considered to be gray space. Instead, if for instance the GRU (Russia's military intelligence agency) controls a node in the Netherlands, it is considered to be red space based on JP 3-12. ${ }^{\mathrm{xx}}$ And it is worth mentioning that the notion of control is open to interpretation by states.

This means that if U.S. Cyber Command seeks to operate only in "red space," its activities will still have global reach. It also suggests that red space grows as adversaries expand their operational activity. Most importantly, this implies that if U.S. Cyber Command seeks to achieve "effects" in gray space, this will involve operating infrastructure that adversaries do not control—which is to say those systems or networks on which adversaries merely have a presence or are not active at all.

What is really new here? The United States has long operated in networks "close to the adversary." As Ben Buchanan's book, "The Cybersecurity Dilemma," demonstrates, the U.S. has long acted as an observer outside of its own networks, gathering intelligence of adversarial activity in those others' networks. ${ }^{x x i}$ In fact, information has become public concerning a case in which the Five Eyes collected intelligence about an espionage platform (dubbed "Snowglobe" by the Canadian Intelligence Agency CSEC and "Animal Farm" by Kaspersky Lab) of an allied country, France, likely operating in adversarial networks in the Middle East. ${ }^{\text {xxi }}$ In other words, the practice of fourth-party collection is nothing new. ${ }^{\text {xiii }}$ Furthermore, the U.S. has long acted in foreign non-adversarial networks as a passerby, transiting through allied' networks to access an adversarial network.

Yet, the new Cyber Command and Defense Department strategy changes the nature of the U.S. military's behavior within those systems and networks. Under the new strategy, Cyber Command wants to be an active disrupter on those networks. It wants to achieve effects - that is to disrupt, deny, degrade, and/or destroy. The only known precedent is U.S. Cyber Command operators wiping Islamic State propaganda material off a server located in Germany. ${ }^{\text {xiv }}$ The German government was notified in some fashion but not asked for advance consent, causing much frustration. ${ }^{\mathrm{xx}}$ This will likely lead to a systematic scaling up: U.S. Cyber Command now also seeks to be an active disrupter on those networks "globally, continuously and seamlessly" — not regionally and sporadically.xxvi 
Out of network operations in allied networks also affect the turf war between the NSA and Cyber Command - mostly critically Title 10 and Title 50 concerns. ${ }^{\text {xxvii }}$ As Chesney summarizes:

From a legal perspective, the issue this [case of Germany] highlights is that operations abroad implicate the UN Charter and related claims about international law protection of sovereignty. [...] Intelligence agencies can more easily act in this setting when operating under Title 50 authority, as covert action status carries with it a statutory obligation to comply with the U.S. Constitution and U.S. statutes - but no more than that. Title 10, in contrast, carries with it no such implicit statutory shield against international law objections, and of course there is a general Defense Department policy of international law compliance. Thus CYBERCOM operating under Title 10 would run into the full thicket of international law concerns. ${ }^{\text {xxviii }}$

Overall, it is expected that operating in allied networks under Title 10 is likely to cause more legal friction than operating under Title 50.

\section{Benefits and the creation of partnerships}

The strategy of persistent engagement and defend forward can help less capable cyber actors defend themselves against adversaries. Both the U.S. Cyber Command vision and the DoD cyber strategy stress the importance of working closely with international and private sector partners to successfully operate in cyberspace. ${ }^{\text {xix }}$ The DoD strategy states the following: "Our strategic approach is based on mutually reinforcing lines of effort to build a more lethal force; compete and deter in cyberspace; expand alliances and partnerships; reform the Department; and cultivate talent." ${ }^{\text {"xx }}$ On international partnerships, it more explicitly states: "Many of the United States' allies and partners possess advanced cyber capabilities that complement our own. The Department will work to strengthen the capacity of these allies and partners and increase DoD's ability to leverage its partners' unique skills, resources, capabilities, and perspectives. Information-sharing relationships with allies and partners will increase the effectiveness of combined cyberspace operations and enhance our collective cybersecurity posture." ${ }^{\mathrm{xxxi}}$

The United States has also signed several memoranda of understanding and over the years addressed cyber cooperation in some way, shape or form. In 2008, a MoU was signed between the Department of Defense and the German Federal Ministry of Defence about computer network defense and information assurance. ${ }^{\text {xxii }}$ A year later, a similar MoU on computer network defense was signed with South-Korea. ${ }^{\text {xxxiii }}$

More recently, the Cyber Command worked alongside Montenegrin cyber defenders with as aim "to increase interoperability, build partner capability, and deter malign influence on the democratic processes of our allies, partners and the U.S." ${ }^{\text {xxxiv }}$ It was reported that U.S. Cyber Command personnel operated in the networks of Ukraine and Macedonia as well to help those countries defend against malicious cyber activity. ${ }^{\text {xxv }}$ At the 2019 Cyber Command symposium, specific examples were discussed on how cooperation can also help in not just detecting or deterring adversaries but also 
cause friction in their operational activity. ${ }^{\text {xxvi }}$ For example, the U.S. might upload foreign APT malware samples on VirusTotal, an online malware repository and file scanning service, forcing adversaries to go back to the drawing broad and adapt. ${ }^{\text {xxvii }}$ One can think of several other scenarios how international partnerships (also with the private sector) can help to ensure more coordinated take down of adversarial operations - actions beneficial to both the US and its partners.

\section{Risks for Allies and Intelligence Collection}

This section addresses four connected risks associated with US strategy. The first risk is perhaps the most obvious: if U.S. Cyber Command directly operates in allied networks without consent, it creates friction by allies undermining trust. Operating instantly makes sense considering the potential operational tempo of adversaries: You cannot have protracted diplomatic discussions for two months with an ally about whether or not to take down some command and control infrastructure of an adversary hosted in the allied country. You don't have days, let alone months. As a participant mentioned at the 2019 Cyber Command Symposium on strategy: "Opportunities within this domain are fleeting., ,xxxviii

Operating seamlessly could also make sense if an ally does not mind the U.S. coming into its networks to address the malicious activity. In this vein, the U.S. can continue to build partnerships with countries that do not have the capacity to defend against cyber attacks on their own, as described above. But, what if an allied country is not keen on having the U.S. military in its networks, actively, seamlessly, and continuously disrupting an adversary's cyber operations? As the German case shows, this scenario will likely come up a lot more in the near future.

Second, it is not just about cyber effect operations taking place in systems or networks in allied territory. There could also be a negative impact on allied intelligence operations and capabilities beyond these systems and networks. The U.S Cyber Command - and other military cyber organizations - are operating in a global environment historically dominated by intelligence agencies, and the Five Eyes has always been the most dominant actor in cyberspace. ${ }^{\text {xxix }}$ But the anglophone intelligence alliance is not the only intelligence actor operating across the world. Recent cases-such as the infiltration of the Dutch General Intelligence and Security Service into the Russia-based network of the infamous hacking group Cozy Bear-have illustrated the continued global prevalence and value of allies' intelligence operations beyond the Five Eyes alliance. ${ }^{x l}$ If U.S. Cyber Command increasingly take up the role of 'disrupter' it may negatively impact global intelligence collection of allies-particularly those countries that favor long-term access over immediate effect. It will also more likely uncover and burn allied capabilities.

The risks of occurring are higher than one may think as intelligence agencies have a tendency and incentive to target and track the same entities. For example, in late 2014, cybersecurity company Kaspersky Lab reported on the so-called "Magnet of Threats". The cybersecurity company discovered 
a server belonging to a research organization in the Middle East that simultaneously hosted implants for at least five Advanced Persistent Threat (APT) actors: Regin and the Equation Group, Turla and ItaDuke, Animal Farm, and Careto. ${ }^{\text {xli }}$ All of these APTs have been associated with prominent national security and intelligence agencies. Equation group and Regin are connected to the Five-Eyes. As said, Animal Farm has been attributed to France's external intelligence agency. Turla Group has been associated with the Russian federal security service (FSB). ItaDuke is said to be linked to the Russian government too. Finally, it is theorized that Spain is behind Careto, also known as 'The Mask'.

Consider what would have happened if one of those five APT groups had sought to cause a disruptive effect - rather than collect intelligence - against the target in the Middle East. It likely would have resulted in much earlier discovery and analysis by threat intelligence companies (or other actors) exposing the tactics, techniques and procedures (T'TPs) of each actor group.

Also, even the anticipation of more cyber effect operations in non-allied networks from one allied state could lead to a change in operations by another state. Indeed, states have shown in the past that the anticipation of early discovery of an operation has led to a change in their TTPs. For example, the National Security Agency (NSA) created an "exploit orchestrator" called FoxAcid, an internet-enabled system capable of attacking target computers in a variety of different ways, depending on whether it is discovered-or likely to be discovered - in a given network. ${ }^{\text {xli }}$ FoxAcid has a modular design, with flexibility allowing the NSA to swap and replace exploits and run different exploits based on various considerations. Against technically sophisticated targets where the chance of detection is high, FoxAcid would normally choose to run low-value exploits.

Third, allied friction could potentially be exploited by adversaries. Adversaries do not randomly choose which intermediate nodes to direct their operations through. If Russia has the choice to go through a network that would raise some serious diplomatic friction between the U.S. and a U.S. ally, or operate through a network that would cause no diplomatic friction for the U.S., what would it prefer?

It would make sense for adversaries to operate through the networks of exactly those countries with which the U.S. has a strong relationship but that do not want the U.S. to operate within their networks causing any effects. Russia is already good at exploiting divisions between the U.S. and its allies. Cyber Command's new strategy might give it another avenue to do so.

Fourth, whilst allies can integrate their cyber efforts into U.S. strategy of persistent engagement, if allies would adopt their own strategy of persistent engagement - mirroring U.S. current doctrine and practice - it would likely further undermine the alliance relationships. If US strategy of persistent engagement leads allies to adopt their own strategy of persistent engagement, it would mean allies also seek "superiority in cyberspace"; "continuously engaging and contesting adversaries and causing them uncertainty wherever they maneuver"; and operating "seamlessly, globally and continuously" - as stated in the Cyber Command vision. More specifically, it would mean that allies seek to swiftly achieve 
effects in systems and networks that are potentially located on U.S. territory, without necessarily notifying the U.S. government before. In other words, it means that networks and systems turn into red space and gray space for allies - like allied networks are now gray and red space for the U.S. to actively disrupt and degrade adversarial operations.

It is unlikely that the U.S. government would react positively if Germany, or any other allied country for that matter, hacks into a server hosting Russian propaganda that was located in the United States, with some form of notification but without Pentagon's consent. ${ }^{\text {xiii }}$ There are numerous reasons why the US government would be upset with this type of behavior. It would likely be seen as reckless from Germany - especially if the US was already on those same networks for intelligence collection purposes.

An important dimension of this scenario is derived from the fact that the U.S. is a vast target rich environment, potentially even prioritized as a target by adversaries such as China, Russia, North Korea, Iran - as well as non-state actors. As stated above, red space and gray space are defined, according to U.S. Joint Publication 3-12 on Cyberspace Operations, based on what "nodes" adversaries "control". There are many nodes adversaries (of US allies) want to control in the US. In other words, if US allies would seek to swiftly disrupt and degrade cyber operations in red space and gray space on a constant-basis, much of that would be in the United States.

Last year the NATO alliance reached a landmark that went largely unnoticed: there are now more NATO member states that have publicly declared they are seeking to establish an institutional capacity within the military forces to conduct cyber effects operations than there are member states that have remained publicly silent on this issue. ${ }^{\text {xliv }}$ Yet, most NATO members are still at the early stages of organizational development - and pour relatively few resources into their military cyber organizations to conduct cyber effects operations. ${ }^{\text {xlv }}$ Their operational capacity is limited. France and Germany stand out for the extent of resources officially allocated to their military cyber organizations (beyond the Five-Eyes) - but public statements about these figures are generally hard to interpret and compare given distinct institutional design across military cyber organizations of states. ${ }^{\text {xlvi }}$ This risk is therefore less significant for the short term, but is likely to grow in the medium to long term.

\section{Conclusion and Discussion}

The purpose of this paper was to provide a benefit-risk assessment of US strategy for its allies and intelligence collection. Whilst the U.S. government's mission to persistently engage with adversaries may have benefits for allied states, the paper identified several avenues how the strategy leads to negative implications for the alliance. To conclude, it is therefore worth considering how these risks can be mitigated. 
First, the principles of persistent engagement and defend forward are often jointly discussed. How the two principles relate to each other, however, remains unclear. According to some, persistent engagement is an 'operationalization' of the defend forward concept. Others believe there is a difference between the two concepts. If the latter is the case, it is important to assess to what degree a strategy of persistent engagement necessitates 'defending forward' and contesting adversaries wherever they are. In other words, the question is whether sufficient friction can be created without causing disruption in allied networks. Second, terminology about terrain in cyberspace is frequently confused by policymakers and experts. The U.S. government needs to (re)assess how its terminology of terrain in the physical domains applies to cyberspace.

Last, NATO allies should consider establishing memoranda of understanding on offensive cyber effects operations in systems or networks based in allied territory. ${ }^{\text {xvii }}$ The goal of the proposed memorandum would be to reduce discord among the allies; enhance trust, transparency and confidence between allies; and improve the effectiveness of disrupting and deterring adversaries' operations in cyberspace. The scope of the memorandum would include: i) developing a common notification equity framework for out-of-networks operations which seek to achieve cyber effects in allied systems or networks; ii) identifying procedures for communicating the consideration and conduct of offensive cyber effects operations between states against systems or networks in allied territory; and iii) identifying technical solutions and administrative documentation required for the continuous exchange of information on offensive cyber operations. In writing the memorandum, states first and foremost should agree on the equities involved in permitting signatories to conduct cyber effect operations in each other's networks - and the relative weight of those equities. Equities that should be considered include: i) the ability of an actor to take action to negate known threats on or to the other parties' networks and systems; ii) the likelihood that an action will negate known threats; iii) the imminence and scale of the threat; iv) the risk of collateral damage; v) whether the computer system or network is government-owned or privately owned; and vi) the certainty that the system or network will be used to achieve strategic effects by the adversary. ${ }^{\text {lviii }}$ Finally, though the memorandum of understanding may help in promoting stability and enhancing confidence amongst allies, it is not a silver bullet. It can only reduce allied concerns rather than mitigate them. Military cyber organizations may still conduct effect-based operations in allied territory without consent, leading allies to assert that their sovereignty has been violated.

Furthermore, there is another crucial player involved. As Gen. Nakasone noted in the Joint Force Quarterly article, cyberspace is owned largely by the private sector. They deserve a seat at the table as well. $^{\text {xlix }}$ 


\section{Acknowledgements}

For written comments on early drafts, I am indebted to Jamie Collier, Florian Egloff, Richard Harknett, Jason Healey, Herbert Lin, James N. Miller, James Shires, and Diana van der Watt. I also thank the participants of the workshop 'The Transatlantic Dialogue on Military Cyber Operations,' held in Amsterdam in August 2019.

\section{Bibliography}

Barnes, J.E. 2019. "U.S. Cyber Command Bolsters Allied Defenses to Impose Cost on Moscow," The New York Times. May. https://www.nytimes.com/2019/05/07/us/politics/cyber-commandrussian-interference.html

Betz, D., and T. Stevens. Cyberspace and the State: Towards a Strategy for Cyber-Power. Abingdon: Routledge, Adelphi Series. 2013.

Bing, C. 2018. "Command and control: A fight for the future of government hacking." Cyberscoop. April 11. https://www.cyberscoop.com/us-cyber-command-nsa-government-hacking-operationsfight/

Borghard, Erica and Shawn Lonergan. 2018. "What Do the Trump Administration's Changes to PPD-20 Mean for U.S. Offensive Cyber Operations?” CFR Net Politics Blog. https://www.cfr.org/blog/what-do- trump-administrations-changes-ppd-20-mean-us-offensivecyber-operations

Buchanan, B and R.D. Williams, 2019. “A Deepening U.S.-China Cybersecurity Dilemma.” Lawfare. October. https://www.lawfareblog.com/deepening-us-china-cybersecurity-dilemma

Buchanan, B. The Cybersecurity Dilemma: Hacking, Trust and Fear Between Nations. Oxford University Press: 2017

Chesney, R. 2018. "Title 10 and Title 50 Issues When Computer Network Operations Impact Third Countries," Lawfare, April 12. https://www.lawfareblog.com/title-10-and-title-50-issues-whencomputer-network-operations-impact-third-countries

Chesney, R. 2018. "An American Perspective on a Chinese Perspective on the Defense Department's Cyber Strategy and 'Defending Forward'.” Lawfare, October. https://www.lawfareblog.com/american-perspective-chinese-perspective-defense-departmentscyber-strategy-and-defending-forward

Chesney, R. 2019. “CYBERCOM's Out-of-Network Operations: What Has and Has Not Changed Over the Past Year?". Lawfare. May. https://www.lawfareblog.com/ cybercoms-outnetworkperations-what-has-and-has-not-changed-over-past-year

Chesney, R. 2018. “The 2018 DOD Cyber Strategy: Understanding 'Defense Forward' in Light of the NDAA and PPD-20 Changes". Lawfare. September. https://www.lawfareblog.com/2018-dodcyber-strategy- understanding-defenseforward-light-ndaa-and-ppd-20-changes 
Cimpanu, C. 2018. "US Cyber Command starts uploading foreign APT malware to VirusTotal," ZDNet. November 8. https://www.zdnet.com/article/us-cyber-command-starts-uploading-foreignapt-malware-to-virustotal/

Delerue, F., A. Desforges and A. Gery, 2019. “A Close Look at France's New Military Cyber Strategy." April. https://warontherocks.com/2019/04/a-close-look-at-frances-new-military-cyberstrategy/

Department of Defense. 2019. "Cyber Strategy 2019: Summary." https://media.defense.gov/2018/Sep/18/2002041658/1/1/1/CYBER_STRATEGY_SUMMARY_FINAL.PDF

DoD News. 2018. "U.S., Montenegro conduct groundbreaking cyber defense cooperation," October. https://www.cybercom.mil/Media/News/News-Display/Article/1651540/usmontenegro-conduct-groundbreaking-cyber-defense-cooperation/

Fischerkeller, M., and R. Harknett, 2019. "A Response on Persistent Engagement and Agreed Competition." Lawfare. June. https://www.lawfareblog.com/response-persistent-engagement-andagreed-competition

Fischerkeller, M., and R. Harknett. 2017. "Persistent Engagement and Tacit Bargaining: A Path Toward Constructing Norms in Cyberspace." Lawfare. November 9. https://www.lawfareblog.com/persistent-engagement-and-tacit-bargaining-path-towardconstructing-norms-cyberspace

Goetz, J., M. Rosenbach and A. Szandar. 2009. "National Defense in Cyberspace." Spiegel. February. www.spiegel.de/international/germany/war-of-the-future-national-defense-in-cyberspace-a606987.html

Goodman, S., J. Kirk, and M. Kirk. "Cyberspace as a medium for terrorists.” Technological Forecasting and Social Change, 74:2 (2007) 193-210

GReAT. 2015. "Animals in the APT Farm.” Securelist. March 6. https://securelist.com/animals-inthe-apt-farm/69114/

Guerrero-Saade, J.A. and C. Raiu. 2017. "Walking in your enemy's shadow: when fourth-party collection becomes attribution hell," Virus Bulletin Conference, https://media.kasperskycontenthub.com/wpcontent/uploads/sites/43/2018/03/07170728/Guerrero-Saade-Raiu-VB2017.pdf

Hathaway, M. 2013. “Cyber Readiness Index 1.0.” Presentation at Science, Technology, and Public Policy Program. Belfer Center for Science and International Affairs, Harvard Kennedy School.

Healey, J. 2018. "Triggering the New Forever War, in Cyberspace/" The Cipher Brief. April. https://www.thecipherbrief.com/triggering-new-forever-war-cyberspace 
Healey, J. “The Implications of persistent (and permanent) engagement in cyberspace.” Journal of Cybersecurity 5:1 (2019) doi: 10.1093/cybsec/tyz008

Jinghua, L. 2018. “A Chinese Perspective on the Pentagon's Cyber Strategy: From 'Active Cyber Defense' to 'Defending Forward'." Lawfare. October. https://www.lawfareblog.com/chineseperspective-pentagons-cyber-strategy-active-cyber-defense-defending-forward

Jinghua, L. 2018. "What Really Matters in 'Defending Forward'?” November. https://www.lawfareblog.com/what-really-matters-defending-forward

Joint Publication 3-12. 2018. "Cyberspace Operations.” June.

https://www.jcs.mil/Portals/36/Documents/Doctrine/pubs/jp3 12.pdf?ver=2018-07-16-134954$\underline{150}$

Kaminska, M., R. Chesney, and M. Smeets. 2019. "A Transatlantic Dialogue on Military Cyber Operations.” Workshop Report. University of Texas at Austin. Amsterdam. August. https://www.strausscenter.org/images/pdf/Amsterdam-Workshop-Report-Final-Oct-1.pdf

Kaspersky, 2017."Spy Wars: How nation-state backed threat actors steal from and copy each other." October 4. https://www.kaspersky.com/about/press-releases/2017_spy-wars-how-nationstate-backed-threat-actors-steal-from-and-copy-each-other

McGhee, J.E. “Liberating Cyber Offense.” Strategic Studies Quarterly. (2016, Winter) 46-63

Miller, J.N., Neal A. Pollard. 2019. "Persistent Engagement, Agreed Competition and Deterrence in Cyberspace.” Lawfare. April. https://www.lawfareblog.com/persistent-engagement-agreedcompetition-and-deterrence-cyberspace $>$

Modderkolk, H. 2018. "Dutch agencies provide crucial intel about Russia's interference in USelections.” De Volkskrant. January 25. https://www.volkskrant.nl/wetenschap/dutch-agenciesprovide-crucial-intel-about-russia-s-interference-in-us-elections $\sim \mathrm{b} 4 \mathrm{f} 8111 \mathrm{~b} /$

Nakashima, E. 2017. "U.S. military cyber operation to attack ISIS last year sparked heated debate over alerting allies." The W ashington Post. May 9). https://www.washingtonpost.com/world/nationalsecurity/us-military-cyber-operation-to-attack-isis-last-year-sparked-heated-debate-over-alertingallies/2017/05/08/93a120a2-30d5-11e7-9dec-764dc781686f story.html

Nakashima, E. 2019. "At nations' request, U.S. Cyber Command probes foreign networks to hunt election security threats." Washington Post. May 8.

https://www.washingtonpost.com/world/national-security/at-nations-request-us-cyber-commandprobes-foreign-networks-to-hunt-election-security-threats/2019/05/07/376a16c8-70f6-11e9-8be0$\underline{\text { ca575670e91c story } \cdot h t m l \text { ?wpisrc }=\text { nl cybersecurity } 202 \& w p m m}=1$

Nakasone, P.M. 2019. “A Cyber Force for Persistent Operations.” Joint Force Quarterly. January. https://ndupress.ndu.edu/JFQ/Joint-Force-Quarterly-92.aspx 
Pomerleau, M. 2019. "New Authorities Mean Lots of New Missions at Cyber Command." Fifth Domain. May 5. https://www.fifthdomain.com/dod/cybercom/2019/05/08/new-authorities-meanlots-of-new-missions-at-cyber-command/

Schneier, B. 2013. "How the NSA Attacks Tor/Firefox Users With QUANTUM and FOXACID." Schneier on Security. October 7.

https://www.schneier.com/blog/archives/2013/10/how the nsa att.html

Schneider, J.G. 2019. "Persistent Engagement: Foundation, Evolution and Evaluation of a Strategy." May. https://www.lawfareblog.com/persistent-engagement-foundation-evolution-and-evaluationstrategy

Smeets, M. "A matter of time: On the transitory nature of cyberweapons." Journal of Strategic Studies, 41:1-2 (2018)6-32. doi: 10.1080/01402390.2017.1288107

Smeets, M. "NATO Members' Organizational Path Towards Conducting Offensive Cyber Operations: A Framework for Analysis," 2019 11th International Conference on Cyber Conflict: Silent Battle, T. Minárik, S. Alatalu, S. Biondi, M. Signoretti, I. Tolga, G. Visky (Eds.), (2019: NATO CCD COE Publications, Tallinn). https://ccdcoe.org/uploads/2019/06/Art_09_NATO-MembersOrganizational-Path.pdf

Smeets, M.W.E and H. Lin. " 4 A Strategic Assessment of the U.S. Cyber Command Vision." in Bytes, Bombs, and Spies: The Strategic Dimensions of Offensive Cyber Operations, edited by H. Lin and A. Zegart, Bookings Institution Press: 2018.

Smeets, M. 2019. “There Are Too Many Red Lines in Cyberspace.” Lawfare. March. https://www.lawfareblog.com/there-are-too-many-red-lines-cyberspace

Unknown., "Memorandum of Understanding Between the Department of Defense of the United States of America and The Federal Ministry of Defense of the Federal Republic of Germany concerning cooperation on Information Assurance (IA) and Computer Network Defense (CND)." https://assets.documentcloud.org/documents/3002259/Document-03.pdf

Unknown., 2009. Memorandum of Understanding Between the Department of Defense of the United States of America and The Ministry of National Defense of the Republic of Korea concerning cooperation on Information Assurance (IA) and Computer Network Defense (CND)." June. https://assets.documentcloud.org/documents/2997984/Document-04.pdf

US Cyber Command. 2018. "2018 Cyberspace Strategy Symposium Proceedings.” https://www.cybercom.mil/Portals/56/Documents/USCYBERCOM Cyberspace Strategy Symposium Proceedings 2018.pdf?ver=2018-07-11-092344-427

U.S. Cyber Command. 2018. "Achieve and Maintain Cyberspace Superiority: Command Vision for US Cyber Command."

https://www.cybercom.mil/Portals/56/Documents/USCYBERCOM $\% 20$ Vision $\% 20$ April $\% 20201$ 8.pdf?ver $=2018-06-14-152556-010$ 
U.S. Cyber Command. 2019. “The 2019 Cyberspace Strategy Symposium,” May. National Defense University, Ft. McNair. 
i US Cyber Command, "Achieve and Maintain Cyberspace Superiority”; Department of Defense, "Cyber Strategy 2019” ii Ibid

iii Note, however, that the strategy itself is silent on this issue as Smeets and Lin note. Also, as Jacquelyn Schneider notes, "It is almost impossible to prove assumptions about escalation. So much of escalation is based on perceptions [..] that it is both impossible to say that an action will never lead to escalation or that it will always lead to escalation."Smeets and Lin, " 4 A Strategic Assessment of the U.S. Cyber Command Vision," ; Schneider, "Persistent Engagement"

iv Healey, "Triggering the New Forever War, in Cyberspace;" Healey, "The Implications of persistent (and permanent) engagement in cyberspace"

$\checkmark$ The paper also provides an excellent historical analysis of the intellectual and policy origins of the new strategy. Healey, "The implications of persistent (and permanent) engagement in cyberspace"

vi Buchanan and RWilliams, "A Deepening U.S.-China Cybersecurity Dilemma;" Chesney, "An American Perspective on a Chinese Perspective on the Defense Department's Cyber Strategy and 'Defending Forward"“; Jinghua, "A Chinese Perspective on the Pentagon's Cyber Strategy;” Jinghua, "What Really Matters in 'Defending Forward'?,"

vii Fischerkeller and Harknett, "A Response on Persistent Engagement and Agreed Competition”; Fischerkeller and Harknett, "Persistent Engagement and Tacit Bargaining"

viii Miller and Pollard, "Persistent Engagement, Agreed Competition and Deterrence in Cyberspace;" Smeets, "There Are Too Many Red Lines in Cyberspace"

ix For early reporting on this see: Pomerleau, "New Authorities Mean Lots of New Missions at Cyber Command;" Borghard and Lonergan; "What Do the Trump Administration's Changes to PPD-20 Mean for U.S. Offensive Cyber Operations?"

x Kaminska, Chesney, and Smeets, “A Transatlantic Dialogue on Military Cyber Operations,” For an excellent, more indepth overview see: Chesney, "CYBERCOM’s Out-of-Network Operations”, Chesney, “The 2018 DOD Cyber Strategy"

xi On how interagency processes impacted the effectiveness and efficacy of cyber operations in the past see: McGhee, "Liberating Cyber Offense"

xii This means that this paper does not seek to provide a general review of persistent engagement and its connected institutional development. For works attempting to conduct this type of exercise see: Smeets and Lin, "Chapter 4: A Strategic Assessment of the U.S. Cyber Command Vision"; Healey, "The implications of persistent (and permanent) engagement in cyberspace"

xiii The meaning of cyber 'capability' or 'power' remains contested. For a discussion see: Betz and Stevens, "Cyberspace and the State: Towards a Strategy for Cyber-Power"; Hathaway, "Cyber Readiness Index 1.0."

xiv US Cyber Command, "Achieve and Maintain Cyberspace Superiority"

xv Ibid

xvi Nakasone, "A Cyber Force for Persistent Operations"

xvii Goodman, Kirk, and Kirk, "Cyberspace as a medium for terrorists"

xviii USCYBERCOM, "2018 Cyberspace Strategy Symposium Proceedings”

xix Joint Publication 3-12, "Cyberspace Operations"

xx Ibid

xxi Buchanan, "The Cybersecurity Dilemma"

xxii GReAT, "Animals in the APT Farm"

xxiii Guerrero-Saade and Raiu, "Walking in your Enemy's Shadow,"

xxiv Nakashima, "U.S. military cyber operation to attack ISIS last year sparked heated debate over alerting allies;" Bing, "Command and control"

xxv Chesney, "Title 10 and Title 50 Issues When Computer Network Operations Impact Third Countries,"

xxvi US Cyber Command, "Achieve and Maintain Cyberspace Superiority"

xxvii Bing, "Command and control: A fight for the future of government hacking"

xxviii Chesney, "Title 10 and Title 50 Issues When Computer Network Operations Impact Third Countries"

xxix US Cyber Command, "Achieve and Maintain Cyberspace Superiority"

xxx Department of Defense, "Cyber Strategy 2019: Summary"

xxxi Department of Defense, "Cyber Strategy 2019: Summary"

xxxii Whilst the U.S. Cyber Command's reported action may have violated Germany's sovereignty, it didn't explicitly violate the MoU. But it wasn't an act of CND; it was, but an act of a computer network attack (CNA), seeking to disrupt, deny, degrade or destroy.; Unknown, "Memorandum of Understanding Between the Department of Defense of the United States of America and The Federal Ministry of Defense of the Federal Republic of Germany concerning cooperation on Information Assurance (IA) and Computer Network Defense (CND)". 
xxxiii "Memorandum of Understanding Between the Department of Defense of the United States of America and The Ministry of National Defense of the Republic of Korea concerning cooperation on Information Assurance (IA) and Computer Network Defense (CND)," (2009, June 2) <

https://assets.documentcloud.org/documents/2997984/Document-04.pdf

xxxiv DoD News, "U.S., Montenegro conduct groundbreaking cyber defense cooperation."

xxxv Nakashima, "At nations' request, U.S. Cyber Command probes foreign networks to hunt election security threats," Barnes, "U.S. Cyber Command Bolsters Allied Defenses to Impose Cost on Moscow."

xxxvi U.S. Cyber Command, "The 2019 Cyberspace Strategy Symposium.”

xxxvii Cimpanu, "US Cyber Command starts uploading foreign APT malware to VirusTotal."

xxxviii U.S. Cyber Command, "The 2019 Cyberspace Strategy Symposium."

xxxix Smeets, "NATO Members' Organizational Path Towards Conducting Offensive Cyber Operations."

${ }^{x l}$ Modderkolk, "Dutch agencies provide crucial intel about Russia's interference in US-elections."

xli Kaspersky, "Spy Wars: How nation-state backed threat actors steal from and copy each other."; Guerrero-Saade and Costin Raiu. "Walking in your enemy's shadow: when fourth-party collection becomes attribution hell"

xlii See the detailed discussion on exploit orchestrator FoxAcid: Schneier, "How the NSA Attacks Tor/Firefox Users

With QUANTUM and FOXACID."; Smeets, "A matter of time"

xliii That is, mirroring the case of the U.S. hacking into the German server.

xliv Joint Publication 3-12, "Cyberspace Operations"

xlv Furthermore, as Schneider notes, the resources to operate seamlessly and continuously are extensive. See: Schneider, "Persistent Engagement"

xlvi Delerue, Desforges and Gery, “A Close Look at France's New Military Cyber Strategy.”; Goetz, Rosenbach and Szandar, "National Defense in Cyberspace"

xlvii As listed above, already memoranda of understanding exist on CND. These MoUs would focus on CNA.

xlviii A pre-operation identification of relevant equities and procedures can also promote operational and tactical effectiveness of cyber command as less decisions have to be made on an ad hoc basis.

xlix Nakasone, "A Cyber Force for Persistent Operations" 